cells in thymus culture ${ }^{18}$ has suggested that the thymus $\mathrm{AChR}$ may act as a stimulus for antibody production, which is subsequently also directed against the neuromuscular junction AChR. Alternatively, the thymus may act as the source of B-lymphocytes or of helper lymphocytes responsible for the continued production of antibody by B-lymphocytes. Culture of thymus tissue showed evidence of synthesis of AChR antibody in one of four patients with myasthenia gravis studied, and two of five patients displayed synthesis of AChR antibody by thymic lymphocytes cultured after thymectomy. ${ }^{19}$

Our failure to show a drop in serum antibody concentrations after thymectomy does not eliminate the possibility that the thymus acts as the source of either the antigen or the antibody. It implies that, by the time of thymectomy, the pathological process may be self-sustaining or the thymus may be an important source of antibody in only a few patients. Alternatively, an as yet unrecognised subpopulation of antibody may be affected by thymectomy, although total antibody concentrations may not be substantially altered.

The lack of apparent relations between serum anti-AChR antibody concentrations in patients with myasthenia gravis and thymectomy and the severity and duration of the disease suggests that if anti-AChR antibodies are the principal pathogenic factor in the disease factors other than the total serum anti-AChR concentration contribute to severity. Immunological variables might include differences in anti-AChR specificity or affinity," in anti-AChR class or subclass effecting complement fixation or antigenic modulation, or in the contribution of cellular immune mechanisms. ${ }^{21}: 2 \cdot 2$ Neurophysiological variables that might contribute to differing responses to the same concentration of serum anti-AChR antibody in different patients include differences in the initial content of $\mathrm{AChR}$ and in the ability of muscle to regenerate AChR or postsynaptic membrane structure. Identification of such immunological or neurophysiological variables would aid understanding of the pathology of myasthenia gravis.

\section{References}

1 Patrick, J, and Lindstrom, J, Science, 1973, 180, 871.

${ }^{2}$ Lennon, V, Lindstrom, J, and Seybold, M, fournal of Experimental Medicine, 1975, 144, 1365 .

${ }^{3}$ Lindstrom, J, et al, Neurology, 1976, 26, 1054.

${ }^{4}$ Lindstrom, J, and Lambert, E, Neurology, 1978, 28, 130.

${ }^{5}$ Lindstrom, J, et al, fournal of Experimental Medicine, 1976, 144, 726.

${ }^{6}$ Fambrough, D, Drachman, D B, and Satyamurti, S, Science, 1973, 182, 293.

7 Engel, A, et al, Neurology, 1977, 27, 307.

${ }^{8}$ Lennon, V, et al, fournal of Experimental Medicine, 1978, 147, 973.

${ }^{9}$ Engel, A, Lambert, E, and Howard, F, Mayo Clinic Proceedings, 1977, 52, 267.

${ }^{10}$ Heinemann, S, et al, Proceedings of the National Academy of Sciences, $1977,74,3090$.

${ }^{11}$ Appel, S, et al, Proceedings of the National Academy of Sciences, 1977, 74, 2130.

12 Kao, I, and Drachman, D B, Science, 1977, 196, 527.

${ }^{13} \mathrm{Dau}, \mathrm{P}$, et al, New England Fournal of Medicine, 1977, 297, 1134

14 Newson Davis, J, et al, Neurology, 1978, 28, 266

15 Scadding, G, Thomas, H, and Havard, C, British Medical fournal, 1977, 1,1512 .

${ }^{16}$ Lindstrom, J, Clinical Immunology and Immunopathology, 1977, 7, 36.

17 Buckingham, J, et al, Annals of Surgery, 1976, 184, 453.

$18 \mathrm{Kao}, \mathrm{I}$, and Drachman, D B, Science, 1977, 195, 74

19 Vincent, A, et al, Lancet, 1978, 1, 305.

${ }^{20}$ Lindstrom, J, Campbell, M, and Nave, B, Muscle and Nerve, 1978, 1, 140.

${ }^{21}$ Abramsky, O, et al, Clinical and Experimental Immunology, 1975, 19, 11.

${ }^{22}$ Richman, D, Patrick, J, and Arnason, B, New England fournal of Medicine, 1976, 294, 694.

(Accepted 30 fune 1978)

\title{
A different kind of day hospital-for patients with preterminal cancer and chronic disease
}

\author{
E WILKES, A G O CROWTHER, C W K H GREAVES
}

British Medical fournal, 1978, 2, 1053-1056

\section{Summary and conclusions}

A new day hospital has been set up in Sheffield for patients with preterminal cancer and chronic disease. During the first 26 months 197 patients with cancer and 66 chronically sick patients attended. Of the 2701 attendances by patients with cancer, breast cancer accounted for $38 \%$. One hundred and forty of the patients with cancer died, $83 \%$ in the terminal-care unit and $12 \%$ at home. Ninety per cent of respondents to a questionnaire thought that the support provided was of great importance to both patient and family; and over two-thirds of

\footnotetext{
Department of Community Medicine, University Medical School, Sheffield S10 2RX

E WILKES, OBE, FRCP, professor of community care and general practice

A G O CROWTHER, MB, BCHIR, general practitioner and honorary lecturer

C W K H GREAVES, вM, всH, general practitioner and teacher of general practice
}

the patients were said to have benefited from improved control of symptoms.

A similar facility could be developed within existing day hospitals without major revenue consequences, and should produce a genuine improvement in care. This study suggests, however, that it would not shorten the terminal stay in hospital.

\section{Introduction}

Most day hospitals are for geriatric or psychiatric patients. We run a day hospital catering for patients with preterminal cancer and chronic disease, which has been developed (mainly through the generosity of the Nuffield Foundation) as an integral part of a terminal-care unit; and we discuss here its first 26 months.

\section{The background}

The 25-bed unit for patients with terminal cancer and the chronic sick is supported by an independent charity but most of the beds are financed by a contract with the area health authority. It takes $350-450$ patients a year, mostly suffering from disseminated cancer; some $12 \%$ of the local cancer deaths occur in the unit, the average stay being 
about two weeks for men and three for women. ${ }^{1}$ In a series of 500 patients the nurses judged the quality of life to have been excellent in $29 \%$, satisfactory in $70 \%$, and poor in only $1-2 \%{ }^{\circ}{ }^{2}$

Nevertheless, we had five grounds for concern. (1) Each year over 100 patients with terminal illness on our waiting list died before we could find them a bed, some of them in most unsatisfactory conditions. (2) We were discharging some $15 \%$ of our patients (who were most commonly admitted to give respite to their families or for the control of symptoms), but they and their families were still under stress and we wanted to keep in touch with them. (3) We were increasingly taking in spouses to share in routine care, but there were many who wished to carry on at home and yet to have help. (4) Most patients die in acute hospitals among strangers, having been at home until near the end ${ }^{2}$; but we hoped that a day unit with a rota of nurses common to the terminal-care unit would mean that patients could be later admitted-if admission were needed-to the care of familiar and trusted staff. (5) Many of the chronic sick, while not bad enough for admission, needed far more than consultations in an outpatient department or with the general practitioner.

We therefore started a day hospital for patients with advanced but not yet terminal cancer and the chronically sick, to enable both patients and their families to live less restricted and unsupported lives.

\section{The unit}

The day unit is purpose built and contains baths, showers, and toilet facilities suited to the disabled. It also has a physiotherapy department, an occupational and recreational therapy room, an area for lunch, and a hairdressing and beauty salon that is very popular.

The unit has a social worker and trained volunteers working under qualified physiotherapists and occupational therapists. But basic nursing also looms large, and there is a sister-in-charge assisted by three other nurses.

Patients attend from 10 am until $3 \mathrm{pm}$, and volunteer drivers (some of whom work in the unit) are invaluable in saving frail patients from delays or circuitous routes. The unit is open five days a week for about 42 weeks a year. When volunteers are short and we close the unit at holiday times we keep contact with those most in need by home visits. In this the community nurse seconded as a liaison nurse is of great value.

\section{The patients}

In the first 26 months 197 patients with preterminal illness and 66 with chronic illness attended the day unit (table I). As with the inpatients, more were in their sixties than any other decade. Attendances totalled $3528,32 \%$ of them being by men and $68^{\circ}{ }_{0}$ by women - there are more women patients, and the long attenders (table II) are mostly women. Whereas nearly $60 \%$ of the women are widowed or single, only $22^{\circ}$ of the men are, and their families are therefore more likely to need support. In 1976 an average of seven patients a day attended and in 197710 ; recently we have had as many as 17 on some days. The increase is due entirely to patients with preterminal cancer.

Patients with preterminal illness are accepted by the day hospital with little delay and attend for as long as they need. Eighty-five per cent come once a week but some with special problems two or three times a week. The relationships that develop are often kept up after patients are admitted to the terminal-care unit, with inpatients visiting their friends in the day unit and joining in activities even from their beds.

We try to limit the chronic sick to about $20^{\circ}{ }_{0}$ of the total. They attend once a week for eight weeks but they are accepted for another eight weeks, when space permits, nine to 12 months later.

\section{Diagnosis and duration of attendance}

Breast cancer is common and is also a lengthy illness (table II); such patients account for $38 \%$ of attendances. Patients with lung cancer account for $17^{\circ}$, . Prostatic and brain tumours often have a prolonged course and patients may attend for many months, whereas those with other common tumours of the genital and gastrointestinal tracts attend for about two months. Patients with cancers in the 12 most common primary sites attend on average 13 times (table III).

TABLE II-Details of patients with cancer ( 3 men and 14 women) attending for 50 or more weeks

\begin{tabular}{|c|c|c|c|}
\hline $\begin{array}{l}\text { Primary site or type } \\
\text { of tumour }\end{array}$ & $\begin{array}{c}\text { No of } \\
\text { patients }\end{array}$ & $\begin{array}{l}\text { Duration or } \\
\text { mean total } \\
\text { duration of } \\
\text { attendance } \\
\text { (weeks) }\end{array}$ & Main problems \\
\hline Breast & 7 & 74 & $\begin{array}{l}\text { Social support (4), pain control } \\
\text { (5), dressings (2), nausea (2), } \\
\text { depression (2) }\end{array}$ \\
\hline Bronchus & 3 & 65 & $\begin{array}{l}\text { Social support (3), depression } \\
\text { (2), dyspnoea (1), pain (1) }\end{array}$ \\
\hline $\begin{array}{l}\text { Prostate } \\
\text { Astrocytoma } \\
\text { Non-Hodgkin's } \\
\text { lymphoma }\end{array}$ & $\begin{array}{l}1 \\
1 \\
1\end{array}$ & $\begin{array}{l}68 \\
97 \\
50\end{array}$ & $\begin{array}{l}\text { Social support, depression } \\
\text { Mobilisation } \\
\text { Social support }\end{array}$ \\
\hline $\begin{array}{l}\text { Stomach } \\
\text { Bladder } \\
\text { Unknown }\end{array}$ & $\begin{array}{l}1 \\
1 \\
2\end{array}$ & $\begin{array}{l}68 \\
56 \\
67\end{array}$ & $\begin{array}{l}\text { Pain, anxiety, cachexia } \\
\text { Nausea, cachexia } \\
\text { Social support, incontinence }\end{array}$ \\
\hline
\end{tabular}

TABLE III-Attendances by patients with 12 most common cancers

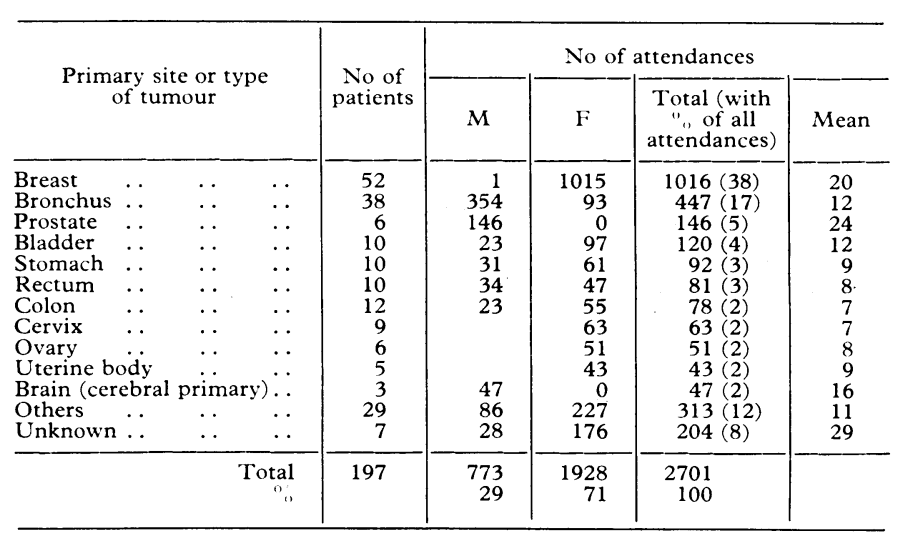

Despite the support of the day hospital, 14 patients (three men and 11 women) had to be admitted as inpatients-in all, 43 times, 21 of the admissions being for breast cancer. Thirty-seven patients attended the unit only once (figure), most being then speedily admitted as inpatients. The main difficulties were pain control $(17$ cases) and $\mathrm{C}$ family problems (13).

Half of the chronically ill patients had had strokes (20) or suffered from multiple sclerosis (14), and there were seven cases each of Parkinsonism and rheumatoid disease. Among the less common $\stackrel{5}{?}$

TABLE I-Patients with preterminal cancer and chronic disease by age and sex during the first 26 months of the day unit

\begin{tabular}{|c|c|c|c|c|c|c|c|c|}
\hline \multirow{2}{*}{$\begin{array}{c}\text { Age } \\
(y)\end{array}$} & \multicolumn{3}{|c|}{ No with cancer } & \multicolumn{3}{|c|}{ No with chronic disease } & \multirow{2}{*}{$\begin{array}{l}" . \text { of total } \\
\text { patients }\end{array}$} & \multirow{2}{*}{$\begin{array}{l}\text { of total } \\
\text { attendances }\end{array}$} \\
\hline & M & $\mathrm{F}$ & Total & M & $\mathrm{F}$ & Total & & \\
\hline $\begin{array}{l}50 \\
51-60 \\
61-70 \\
71-80 \\
>80 \\
\text { Not known }\end{array}$ & $\begin{array}{r}3 \\
16 \\
30 \\
22 \\
5 \\
1\end{array}$ & $\begin{array}{r}15 \\
22 \\
39 \\
30 \\
13 \\
1\end{array}$ & $\begin{array}{r}18 \\
38 \\
69 \\
52 \\
18 \\
2\end{array}$ & $\begin{array}{r}2 \\
6 \\
10 \\
9 \\
1 \\
0\end{array}$ & $\begin{array}{r}6 \\
5 \\
16 \\
9 \\
0 \\
2\end{array}$ & $\begin{array}{r}8 \\
11 \\
26 \\
18 \\
1 \\
2\end{array}$ & $\begin{array}{r}10 \\
19 \\
36 \\
27 \\
7 \\
1\end{array}$ & $\begin{array}{r}12 \\
17 \\
33 \\
26 \\
11 \\
1\end{array}$ \\
\hline Total & 77 & 120 & 197 & 28 & 38 & 66 & 100 & 100 \\
\hline
\end{tabular}




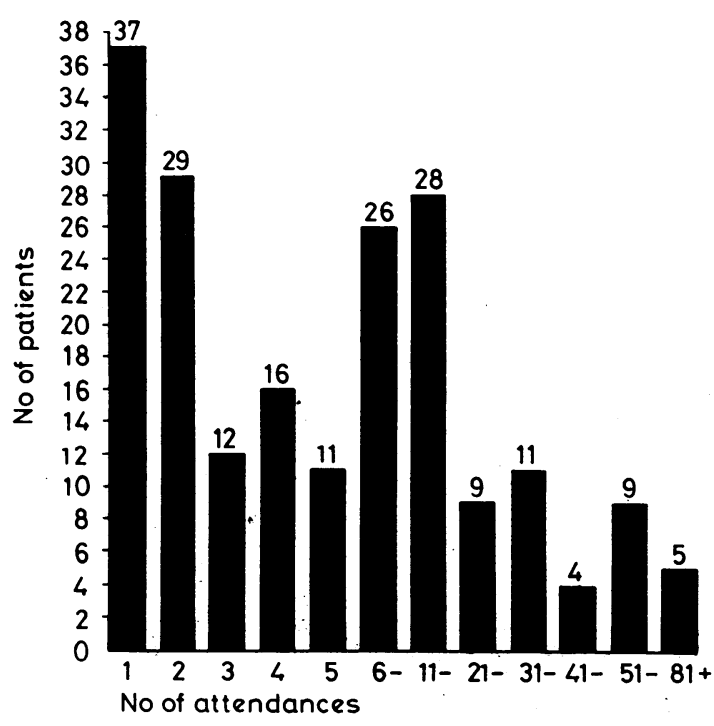

Attendances at the day unit over 26 months.

diseases were motor neurone disease, severe chronic respiratory disease, presenile dementia, and cervical arachnoiditis.

\section{Absences, deaths, and patient flow}

There were 442 absences, a rate of $12.5 \%$. Only $2 \%$ were due to defaulters who did not like the unit. Nearly half of the absences were because patients were too ill to attend, and a quarter because they had been admitted to our hospital or elsewhere.

Four of the 66 chronically sick patients and 140 of the 197 cancer patients died; of the latter, 116 died in our inpatient unit, 17 at home, and 7 in other hospitals. Thus there were about six deaths a month among the day-unit patients, with new patients making up from a quarter to a third of those attending.

In the first year we discharged from the inpatient unit 32 patients who had attended the day hospital and in the second year 45 , and deaths at home rose from six to nine. The rate of discharge home from the inpatient unit, however, remains at $13 \%$-the same as before the day unit opened.

The time spent in the inpatient unit before death also seems to be unaffected by attendance at the day hospital- $29 \%$ die within three days after admission and $42 \%$ from four to 14 days, whether they are admitted via the day hospital (as are $16 \%$ of our terminal patients) or via the GP or an acute hospital. Thus we should not wish to shorten the terminal stay in the inpatient unit any more just because we have the day hospital. Despite the pressures on the inpatient unit, we try to keep a bed there empty for day patients in emergency; this is not too difficult since both patients and nurses need a day of mourning after someone dies before the bed is filled again.

\section{Rehabilitation and other needs}

Half the patients with preterminal cancer had obvious social and emotional needs, while a quarter needed general nursing care and a quarter more effective control of pain, nausea, vomiting, constipation, etc (table IV). The chronically sick patients had less pain and more social problems-especially a need for social stimulus and better support for the family.

Since one of the main purposes of the day hospital is to prolong independence as comfortably as possible for as long as possible, the physiotherapist and occupational therapist play a crucial part. Fiftyeight per cent of the patients received physiotherapy; $10 \%$ refused it, $20 \%$ did not need it, and $12 \%$ were too ill for anything more than undemanding group exercises that could be performed if necessary in a wheelchair. The most common need, in $28^{\circ} \%$ of patients, was help in mobilisation.

The occupational therapy transformed the atmosphere of the day unit. Sixty-two per cent of patients were very keen on it, $19 \%$ were not so keen, $6 \%$ refused it, and $4 \%$ were too ill. By selling the products at a small charge the cost of materials can be largely recouped.
The most unlikely people enjoyed simple, repetitive tasks such as making plant-pot holders and sticking shells on wine bottles for table lamps, or showed enthusiastic talent for painting, pottery, or making mosaic trays. Items made by dying patients must be treated with respect. However humble and badly made (some need tactful revision by staff), they are very important to relatives. The men especially enjoyed growing sweet peas and tomatoes on the verandah. Those who took less part in occupational therapy often enjoyed music or bingo (which should be organised to provide a lot of cheap prizes). The needs of more intellectual patients must not be neglected, and some of them particularly appreciated the chapel services.

TABLE IV-The patients' main problems*

\begin{tabular}{|c|c|c|}
\hline \multirow{2}{*}{ Problems } & \multicolumn{2}{|c|}{ No $(\%)$ of patients } \\
\hline & Cancer & Chronic disease \\
\hline 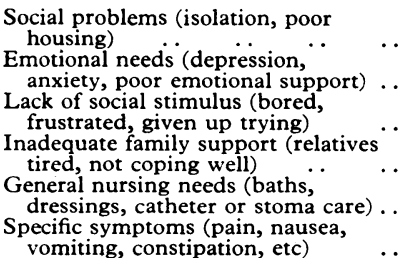 & $\begin{array}{c}59(14) \\
65(16) \\
42(10) \\
40(9) \\
107(25) \\
110(26)\end{array}$ & $\begin{array}{l}20(16) \\
20(16) \\
27(21) \\
26(20) \\
17(13) \\
18(14)\end{array}$ \\
\hline
\end{tabular}

*Many patients had several major problems.

\section{Survey of patients and relatives}

Since our day unit was costing over $£ 20000$ a year we attempted to assess its usefulness further by sending a questionnaire to the bereaved relatives of the patients with cancer and to the chronically ill patients who had attended. Not surprisingly, only half completed the forms and the results cannot be statistically valid, but some interesting facts emerged.

We received replies from 65 relatives of patients who had died. Of these, 51 graded the unit as excellent, seven as good, and one as satisfactory. Fifty-eight families had been greatly helped by having a day off. One relative wrote, "I felt supported at last," and many made similar remarks. Forty-four of the patients were said to have greatly enjoyed their visits, and 16 to have enjoyed them a little; seven had attended as a duty. Patients had apparently liked the company, the change of scene, and the occupational therapy; the visits had given them something to look forward to. One relative said that they had been "always pleased to see how much more cheerful she was after a day-unit visit." At least 45 had found relief from physical problems; some of these could have been more easily helped by admission but had preferred to battle on at home. Most had enjoyed the journey to the day hospital but some found the work and the pain of getting ready a burden.

Of the 23 chronically sick patients who replied to the questionnaire, all but one had much enjoyed their visits and found they helped their own and their families' morale and also their physical problems. Most of all they enjoyed meeting people, but feeling useful and having something to look forward to were also important. Twenty graded the unit as excellent and two as good.

\section{Discussion}

A day unit for those with terminal cancer, though it does not necessarily postpone the final admission to hospital, does provide a rallying point for the patient and family that is beyond the scope of routine hospital and general practitioner services. Clinical and social needs cannot be disentangled, and the administrative separation of the resources of social services, hospital, and primary care is unhelpful to our patients.

Despite the difficulties of transporting sick people across a city, the value of such a unit, in circumstances such as ours, seems clear. Even chronically ill patients with their symptoms mostly under control benefited, and we were surprised how much we could help their long-standing disabilities.

In those urban areas where supportive medical care seems 
most difficult to organise such a unit could be grafted on to existing day hospitals to avoid capital expenditure and large running costs. Certainly a day unit or domiciliary service represents a relatively easy way of starting to meet the needs of dying patients and their families; but a back-up of beds and hospital facilities is also needed $-83 \%$ of our patients died as inpatients. Moreover, patients seem to find it convenient and reassuring to have the day hospital integrated with the inpatient unit. We believe that this should be the arrangement of choice and the pattern of the future.

Mrs Linda Liddamant collected and analysed the data under the supervision of Mrs Maureen Naylor. Secretarial assistance was provided by Mrs Sheila Harris. Valuable advice was received from Professor J Knowelden. Grateful thanks are due to the nurses, rehabilitation professionals, and all other colleagues who have sustained this enterprise.

\section{References}

1 Wilkes, E, Proceedings of the Royal Society of Medicine, 1974, 67, 1001

2 Wilkes, E, Nursing Times, 1977, 73, 1506.

3 Ward, A M W, Social Science and Medicine, 1974, 8, 413.

(Accepted 17 fuly 1978)

\title{
Detection of a new antibody system reacting with Dane particles in hepatitis $B$ virus infection
}

\author{
A ALBERTI， S DIANA， G H SCULARD, A L W F EDDLESTON, ROGER WILLIAMS
}

British Medical fournal, 1978, 2, 1056-1058

\section{Summary and conclusions}

Antibodies in the serum reacting with antigens on the surface of radiolabelled Dane particles distinct from hepatitis $B$ surface and core antigens (HBsAg and HBcAg) were detected, using a double antibody precipitation assay, in 12 out of 15 patients early in the course of acute type $B$ hepatitis and at the time of disappearance of circulating Dane particles. No such antibody activity was found in 15 of the 16 patients with HBsAg-positive chronic active hepatitis, 13 of whom had complete Dane particles in the serum. In a group of 16 asymptomatic HBsAg carriers (without Dane particles in serum) antibody activity was shown in nine.

This demonstration of antibodies precipitating Dane particles may be relevant to the clearance of circulating hepatitis $B$ virions and the termination of infection in acute type $B$ hepatitis. Their absence in all but one of the cases of chronic active hepatitis might explain why the virus infection persists in this group of patients.

\section{Introduction}

Recovery from acute hepatitis type $\mathrm{B}$, as with many other virus infections, is probably a complex process in which lymphocytes, macrophages, neutralising antibody, and interferon all play a part. Cytotoxic, virus-specific $\mathrm{T}$ lymphocytes ${ }^{12}$ are likely to be important in removing infected hepatocytes, but the mechanisms that prevent reinfection of liver cells and clear the virus from the

Liver Unit, King's College Hospital and Medical School, London SE5 A ALBERTI, MD, research fellow (present address: Instituto di Medicina Clinica, Patologia Medica, Policlinico dell Universita, 35100 Padova, Italy)

$S$ DIANA, MD, research fellow

G H SCULLARD, MB, MRCP, research fellow

A L W F EDDLESTON, DM, MRCP, senior lecturer and consultant physician

ROGER WILLIAMS, MD, FRCP, director and consultant physician circulation are poorly understood. Dane particles, which represent the complete hepatitis $B$ virion, ${ }^{3} \cdot$ disappear from the blood early in the course of acute hepatitis B, while the small round particles consisting solely of surface coat antigen ( $\mathrm{HBsAg}$ ) usually persist for much longer. ${ }^{4}$ Detection of anti-HBs is a late and inconstant finding, ${ }^{3}$ and although antibody reacting with the core of the Dane particle (anti-HBc) is present earlier in the illness, this does not react with the intact virion and cannot, therefore, be implicated in clearance of the virus. In healthy HBsAg carriers large amounts of $\mathrm{HBsAg}$ but not of Dane particles are usually detected in serum. ${ }^{7}$ Thus the immune mechanisms responsible for removing Dane particles may be different from those involved in $\mathrm{HBsAg}$ clearance. Indeed, aggregation of Dane particles by sera free of anti-HBs has been shown by electron microscopy. ${ }^{8}$

We report here the detection in acute type $B$ hepatitis of antibodies reacting with new specificities on Dane particles. The absence of such anti-Dane activity in most cases of chronic active hepatitis may explain the persistence of hepatitis $B$ virus infection in these patients.

\section{Patients and methods}

We investigated three groups of patients. Fifteen patients had acute hepatitis type B; within three months of the onset of hepatitis they recovered completely and $\mathrm{HBsAg}$ was cleared from their sera. Sixteen patients had HBsAg-positive chronic active hepatitis proved on biopsy; at the time of presentation eight were untreated while eight had been on immunosuppressive drugs (prednisolone and azathioprine) for four to 24 months. The third group comprised 16 asymptomatic $\mathrm{HBsAg}$ carriers whose liver biopsies showed either normal histology (seven cases); minor abnormalities including hydropic changes (one case) or fatty changes (one case); or focal parenchymal necrosis (seven cases). All the carriers with focal parenchymal necrosis and the carrier with hydropic changes had only scattered liver cells positive for HBsAg in the cytoplasm of the hepatocytes as shown by the orcein method or by immunofluorescence, while in the other eight patients there were many sheets of $\mathrm{HBsAg}$-positive cells. ${ }^{9}$

RADIOIMMUNOASSAY FOR ANTIBODIES TO DANE PARTICLES

The principle of the assay is to label complete Dane particles with ${ }^{3} \mathrm{H}$-thymidine using their own endogenous DNA polymerase and then to incubate them with the serum under test. Antibody-coated virions 